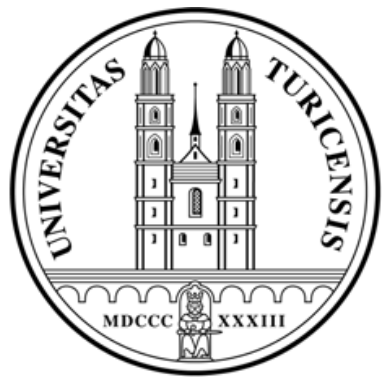

Institute for Empirical Research in Economics

University of Zurich

Working Paper Series

ISSN 1424-0459

Working Paper No. 207

The Importance of Firms in Wage Determination

Max Gruetter, Rafael Lalive

October 2004 


\title{
The Importance of Firms in Wage Determination
}

\author{
Max Gruetter, University of Zurich, IZA* \\ Rafael Lalive, University of Zurich, CESifo, IZA
}

October 15, 2004

\begin{abstract}
Firms are central to many theories of the labor market. However, the extent to which firms affect wages has only recently been explored using matched employer-employee data. This paper investigates (i) the importance of firms in explaining wage differences across individuals and industries, and (ii) how the nature of interfirm mobility - job-to-job vs. job-unemployment-job - affects the relative importance of firms and workers in wage determination. Results indicate that (i) firms are much more important in explaining the variance of average wages across industries rather than individuals, and (ii) using job-to-job transitions reduces the importance of firm wage policies in explaining differences.
\end{abstract}

JEL-Classification: C23, J31

Keywords: interfirm mobility, wage determination, industry wage differentials, matched employer employee data

${ }^{*}$ We thank Erling Barth, Martin Brown, Harald Dale-Olsen, Alfred Garloff, Francis Kramarz, Edwin Leuven, David Margolis, Josef Zweimüller, and seminar participants at IEW, ISF, and IZA for comments on previous versions of this paper. Financial support by the Swiss National Science Foundation (No. 101412-103970) is gratefully acknowledged. Corresponding author: Max Gruetter, Institute for Empirical Research in Economics (IEW), Bluemlisalpstr. 10, CH-8006 Zurich, max.gruetter@iew.unizh.ch; Rafael Lalive, Institute for Empirical Research in Economics (IEW), Bluemlisalpstr. 10, CH-8006 Zurich, rlalive@iew.unizh.ch. 


\section{Introduction}

"Is the variation between the price of labor in different plants almost as large as the variation in hourly earnings, or is it considerably less?" (Slichter (1950), p. 90.)

Firms are central to many theories of the labor market. For instance, the classical view emphasizing that wages reflect marginal productivity holds that wages differ across firms because firms utilize capital to different degrees or offer workplaces that differ with respect to amenities (Rosen (1986); Cahuc, Gianella, Goux, and Zylberberg (2002)). Since wages may be the carrot that motivates employees to provide effort firms that find it hard to monitor workers offer higher wages - the efficiency wage view (Shapiro and Stiglitz (1984), Krueger and Summers (1987)). The theory of the labor market emphasizing institutions argues that differences in unionization rates explain wage differences across firms (Booth (1995), Margolis and Salvanes (2001)). Equilibrium search theory rationalizes wage differentials across firms for homogenous workers due to search frictions (Burdett and Mortensen (1998); van den Berg and Ridder (1998); Postel-Vinay and Robin (2002); Mortensen (2003)). Finally, since the elasticity of labor supply facing the firm is finite, monopsony theory also rationalizes a strong role for firms in wage determination (Manning (2003)). Indeed, Slichter (1950) argues that the answer to his question cited above allows "to speculate concerning the effects of the wage structure upon the distribution of resources among places, firms, and industries." (p. 90)

However, for a long time period, it was not possible to assess the actual wage setting policy of firms because the available micro data-sets did not allow separating the 'price of labor across plants' from the effect of skill differences across workers. The seminal work by Abowd, Kramarz, and Margolis (1999b) used matched employer-employee compensation information to provide a first assessment of the relative importance of firms and workers in wage determination for France. Using an approximate method they show that personal heterogeneity is far more important in explaining variations in the wage rates across individuals as well as across industries. ${ }^{1}$ Abowd, Creecy, and Kramarz (2002) state in a subsequent study using the exact solution instead of the approximate solution that the results for individuals but not for industries are robust. Thus the approximate method is sensitive to an underspecified conditioning matrix. All existing studies suffer from the problem that the mobility decision which is essential to disentangle the person and the firm component is modelled exogenous but the data used are not controlled for endogenous mobility.

This paper reassesses the method developed by Abowd, Kramarz, and Margolis (1999b) using a modified version of the exact method in Abowd, Creecy, and Kramarz (2002) and discussing

\footnotetext{
${ }^{1}$ Further studies have investigated differences between the U.S. and France (Abowd and Kramarz (1999)). The results differ slightly in the sense that firm's and worker's heterogeneity are comparably important on the industry level in the U.S..
} 
the relevance of endogenous mobility. First, we introduce a new statistic to document the extent to which firms contribute to wage differences. We define the importance of firms in wage determination as the share of the total variance that is due to the firm's wage policy - a concept that is directly inspired by Slichter's 1950 question. ${ }^{2}$ We then use this novel statistic to contrast the extent to which differences in wage policies across individual firms explain the total variance in wage rates with the importance of firms in explaining industry wage differences. This contrast allows inferring more closely to what extent the industry category reflects firm differences rather than worker differences. In contrast to Abowd, Kramarz, and Margolis (1999b) our findings indicate that firms are much more important in explaining the variance in average wages across industries than across individuals. Whereas firms account for about one quarter of the total variance in individual wage rates, industry average firm wage policies contribute three quarters of the total variance of average wages across industries. Thus industries are a relatively good proxy for firms.

In a second step, we discuss how the nature of interfirm mobility affects the relative importance of firms and workers in wage setting. Intuitively, the wage policy of the firm is revealed when workers move between firms. This paper argues that it is useful to distinguish between at least two fundamentally distinct types of interfirm mobility ${ }^{3}$ in order to study the degree to which endogenous mobility affects identification of the firm's wage policy: job-to-job (JTJ) transitions on the one hand and job-unemployment-job (JUJ) transitions on the other hand. Workers changing directly from one employer to another employer are likely to do so because the new employer offers a superior wage rate. Thus, the wage change due to a JTJ transition reflects both, the wage policy of the new firm as well as the wage policy of the previous employer. In contrast, workers who enter unemployment between jobs compare the wage rate offered with income while unemployed. To the extent that unemployment benefits are actually lower than income on the previous job, the wage rate in the previous job is less important for the wage rate accepted by the unemployed worker than for the wage rate accepted by a job-to-job mover. Findings indicate that reliance on JTJ mobility in identifying firms' wage policies leads to a reduction in firms' importance in wage determination.

This paper is closely related to two important strands of the literature. First, the literature on wage determination has focused strongly on industry wage differentials. Originally, Slichter (1950) investigated industry wage differentials for relatively homogenous male unskilled labor in order to detect the basic forces that shape the wage structure. The idea was that, if these workers are indeed completely homogenous, these industry wage differentials reflect differences in the "typical" wage policy of firms across industries. Subsequently, a large body of the literature has built up that investigated the original results of strong variation in average wages

\footnotetext{
${ }^{2}$ In contrast, the existing literature uses the correlation between wages and the firms' wage policies to discuss the relevance of firms in wage setting. The correlation statistic can not be interpreted as the share of the total variance in wage rates that is due to firms. Groshen (1991) also uses this concept.

${ }^{3}$ Note that we use the term inter-firm mobility and job mobility synonymously in the remainder of this paper.
} 
across industries for different countries, time periods, and with more rigorous statistical methods (Murphy and Topel (1987), Krueger and Summers (1987), Krueger and Summers (1988), Dickens and Katz (1987)). ${ }^{4}$ Arguing that industry mobility is endogenous, important work by Gibbons and Katz (1992) discusses whether or not industry wage differentials reflect remuneration for skills or pure rents. ${ }^{5}$ This paper contributes to the inter-industry wage differentials literature in contrasting the extent to inter-industry wage differences reflect firm wage setting with the individual level. Second, our paper is closely related to the literature that studies the inter-relationship between wage growth and labor mobility (Antel (1991), Topel and Ward (1994), Farber (1999)). We study the extent to which differences in inter-firm mobility lead to different conclusions regarding the importance of firms in wage setting. This contrast is inspired by the literature that discusses endogenous job mobility and industry wage setting (Gibbons and Katz (1992)). The novel feature of our analysis is, however, that we rely on the two most common types of inter-firm mobility - job-to-job and job-unemployment-job mobility - rather than the much more seldom mobility due to plant closure. This is advantageous for the purpose of this paper since we aim at decomposing wages into worker and firm effects for as large a share of the underlying population of firms and workers as possible. ${ }^{6}$

The empirical analysis is based on a matched employer-employee dataset that covers a $25 \%$ random sample of men working 1990 until $1997^{7}$ in Austria. This main dataset contains information on total compensation, various demographic characteristics, and a workplace identifier. A total of 2,090,483 observations cover 378,244 different persons and 103,346 firms. The analysis is also based on two sub-samples of movers in order to discuss the extent to which inter-firm mobility affects identification of firms' contribution to wage setting. The job-to-job (JTJ) sample considers workers who have moved between employers at least once and always did so directly from job to job. The job-unemployment-job (JUJ) sample considers all workers who have moved between employers at least once and all moves between jobs involved a spell of unemployment. The crucial difference between both sample is that all persons in the JTJ sample changed their job voluntary while all persons in the JUJ sample had to change employers because they had to find a new job. Because the conditioning method proposed in Abowd, Kramarz, and Margolis (1999b) is not robust, all results are based on a modified version of the exact method in Abowd, Creecy, and Kramarz (2002) that decomposes the wage rate into a worker component, a firm

\footnotetext{
${ }^{4}$ See for example Carruth, Collier, and Dickerson (1999) for the UK, Goux and Maurin (1999) for France, Vainiomki and Laaksonen (1995) for Finland or Winter-Ebmer (1994) for Austria. Kahn (1998) and Zweimueller and Barth (1994) study the inter-relationship between industry wage differences and unionization rates.

${ }^{5}$ Recently, Gibbons, Katz, Lemieux, and Parent (2002) extend the original Gibbons and Katz (1992) framework. Kim (1998) argues that industry wage differentials reflect compensation for match specific productivity.

${ }^{6}$ The potential cost to taking this perspective is identification. However, note that under some conditions that we discuss in the following section, contrasting the most common types of inter-firm mobility suffices to identify the extent to which endogenous mobility affects the importance of firms in wage setting.

${ }^{7}$ We use Oktober 10 as valuation date because this is a date where neither the summer nor the winter tourism is dominant.
} 
component, and a transitory component.

The following section presents the statistical model, provides the definition of the importance of firms in wage determination, and discusses endogenous mobility. In section 3 , we describe the data, discuss the main variables, and present descriptive analysis of wage differentials and the patterns of job mobility across 39 industries in Austria. Section 4 presents the main results, and section 5 concludes.

\section{Measuring Firm Wage Policies}

This section discusses the decomposition of the log of the wage rate into a worker effect, a firm effect, and an error term. Having these effects in hand we define how we measure the importance of firms in wage setting. In a last step we show via an example the consequence of interfirm mobility on the estimation of the coefficients.

\subsection{Decomposing Wages}

Let $y_{i t}$ be the $\log$ of the wage rate of worker $i$ at time $t$, let $x_{i t}$ denote the time-varying characteristics, let $s_{J(i t)}$ denote years of seniority of worker $i$ at time $t$, and let $J(i, t)$ be the employer identification number of worker $i$ at time $t$. The number of workers in the dataset is $N$, the number of firms is $J$, and the number of observations is $N^{*}$. We assume that

$$
y_{i t}=x_{i t} \beta+\theta_{i}+\phi_{J(i, t)}+\gamma_{J(i, t)} s_{J(i t)}+\epsilon_{i t}
$$

and

$$
E\left[\epsilon_{i t} \mid i, t, J(i, t), x_{i t}\right]=0
$$

The wage policy of the firm is modelled as simple as possible. ${ }^{8}$ The entry wage, $\phi_{j}$, captures the wage differential earned in the present firm compared to the average firm in the dataset $(j=1, \ldots, J)$. The tenure effect, $\gamma_{j}$, captures differences across firms in the wage increases due to changes in seniority $(j=1, \ldots, J)$. Thus, the contribution of the firm to the wage rate of worker $i$ in period $t$ is $\psi_{i t} \equiv \phi_{J(i, t)}+\gamma_{J(i, t)} s_{i t}$. The worker's wage component, $\theta_{i}$, reflects differences in pay due to time-invariant characteristics of each worker $(i=1, \ldots, N)$. Thus, $\theta_{i}$ measures the extent to which compensation for skill is important. Finally, the parameter $\beta$ measures economy-wide returns to experience or productivity increases (see following section for a definition of $X)$.

The main statistical assumption is exogenous mobility in equation (2). This assumption rules out any correlation between unmeasured time-varying effects on the wage rate captured by $\epsilon_{i t}$ with the person effect $\theta_{i}$, the firm effects or the time-varying observed effects $x_{i t}$.

\footnotetext{
${ }^{8} \mathrm{~A}$ more elaborate model for the wage policy allows for non-linearity in returns to seniority. However, keeping the wage policy of the firm as simple as possible allows identifying the wage policy for a large number of firms.
} 
Direct estimation of the model (1) by least squares is difficult due to computer memory constraints (Abowd, Kramarz, and Margolis (1999b)). This paper uses a modified version of the iterative algorithm proposed in Abowd, Creecy, and Kramarz (2002) to solve for the least squares parameter estimates $\widehat{\beta}, \widehat{\theta}_{i}, \widehat{\phi}_{j}$, and $\widehat{\gamma}_{j}$ (see appendix for a description of our algorithm).

\subsection{The Importance of Firms in Wage Determination}

We propose to measure the importance of firms in wage setting by the contribution of firms to the overall variance in wage rates. In introducing this statistic, note that the total variance in wages $\operatorname{var}\left(y_{i t}\right)$ can be decomposed into a term reflecting covariance of the wage rate with the wage policy of the firm, covariance of the wage rate with worker skills, and covariance of the wage rate with the transitory component of wage rates, i.e. $\operatorname{var}\left(y_{i t}\right)=\operatorname{cov}\left(y_{i t}, y_{i t}\right)=$ $\operatorname{cov}\left(y_{i t}, \widehat{\psi_{i t}}\right)+\operatorname{cov}\left(y_{i t}, \widehat{\theta_{i}}+x_{i t} \widehat{\beta}\right)+\operatorname{cov}\left(y_{i t}, \widehat{\epsilon_{i t}}\right)$. Thus, defining the importance of firms in wage setting as the covariance between the firms' contribution with the wage rate relative to the overall variance

$$
\widehat{\nu}_{f} \equiv \frac{\operatorname{cov}\left(y_{i t}, \widehat{\psi}_{i t}\right)}{\operatorname{var}\left(y_{i t}\right)}=\frac{\operatorname{var}\left(\widehat{\psi}_{i t}\right)}{\operatorname{var}\left(y_{i t}\right)}+\frac{\operatorname{cov}\left(x_{i t} \widehat{\beta}+\widehat{\theta}_{i}, \widehat{\psi}_{i t}\right)}{\operatorname{var}\left(y_{i t}\right)}
$$

ensures a full decomposition of the total variance in wage rates into a firm component, $\widehat{\nu_{f}}$, a worker component, $\widehat{\nu_{p}} \equiv \operatorname{cov}\left(y_{i t}, x_{i t} \widehat{\beta}+\widehat{\theta}_{i}\right) / \operatorname{var}\left(y_{i t}\right)$, and a transitory component, $\widehat{\nu_{\epsilon}} \cdot{ }^{9} \mathrm{~A}$ useful interpretation of $\widehat{\nu_{f}}$ is the following. The importance of firms predicts the (unobserved) expected difference in the firms' contribution $\widehat{\psi_{i t}}$ as a function of the (observed) wage rate. This is true because $\widehat{\nu_{f}}$ gives the derivative of the conditional expectation of the firm's contribution to wages due to a change in the wage rate in a linear regression framework, i.e. $\partial E\left(\widehat{\psi}_{i t} \mid y_{i t}\right) / \partial y_{i t}=$ $\operatorname{cov}\left(y_{i t}, \widehat{\psi}_{i t}\right) / \operatorname{var}\left(y_{i t}\right){ }^{10}$

Equation (3) shows that firms can be important in wage determination for two reasons. First, firms generate strong wage differentials if there are weightily reasons for firms to offer different wages to observationally equivalent workers. This reason shows up as a high relative variance of the firms' contribution. This variance term $\left(\operatorname{var}\left(\widehat{\psi}_{i t}\right) / \operatorname{var}\left(y_{i t}\right)\right)$ also answers directly Slichter's (1950) question cited in the introduction. Second, firms can also amplify the total variance in wage rates in attracting more productive workers. This second reason shows up as a strong covariance term. Note that from the labor economists point of view, assessing the relative importance of these two reasons is important. Whereas strong variance in the firm specific wage component lends support to theories emphasizing the reasons for different compensation packages, strong covariance is in support of other theories that explain how workers and firms

\footnotetext{
${ }^{9}$ Note that the covariance between the firm's contribution $\widehat{\psi_{i t}}$ with the error term $\widehat{\epsilon_{i t}}$ is zero by virtue of exogenous mobility imposed on the estimates by least squares.

${ }^{10}$ For instance, suppose two workers are employed in different firms with worker 1 earning $w_{1}$ and worker 2 earning $w_{2}$. We can say that the firms' contribution is expected to differ by $\widehat{\nu}_{f}\left(w_{1}-w_{2}\right)$.
} 
are matched on the labor market. ${ }^{11}$

Based on the wage decomposition framework (1) it is also possible to address the question to what extent the raw industry wage differentials reflect differences in the "typical" wage policy across industries as opposed to differences in the worker characteristics across industries. The seminal paper by Abowd, Kramarz, and Margolis (1999b) shows that the raw industry wage differential $\widehat{\kappa}^{* *}$ obtained in a cross section regression of wages on the observable characteristics $\left(x_{i t}\right)$ and a set of industry indicators consists of an industry specific firm effect $\left(\widehat{\kappa}^{f}\right)$, and an industry specific person effect $\left(\widehat{\kappa}^{p}\right) .{ }^{12}$ This means that we can define the importance of firms in industry wage determination by the contribution of the industry specific firm effect $\widehat{\kappa}^{f}$ to the total variance in the raw industry wage differential,

$$
\widehat{\mu_{f}} \equiv \frac{\operatorname{cov}\left(\widehat{\kappa}^{* *}, \widehat{\kappa}^{f}\right)}{\operatorname{var}\left(\widehat{\kappa}^{* *}\right)}=\frac{\operatorname{var}\left(\widehat{\kappa}^{f}\right)}{\operatorname{var}\left(\widehat{\kappa}^{* *}\right)}+\frac{\operatorname{cov}\left(\widehat{\kappa}^{p}, \widehat{\kappa}^{f}\right)}{\operatorname{var}\left(\widehat{\kappa}^{* *}\right)}
$$

Equation (4) shows two reasons for a strong contribution of firms to the variance of wages across industries. First, firms are important for industry wage differentials, if the variance in 'average firm wage policies' is strong $\left(\operatorname{var}\left(\widehat{\kappa}^{f}\right) / \operatorname{var}\left(\widehat{\kappa}^{* *}\right)\right)$. Second, strong sorting of high wage workers into high wage industries will increase the contribution of firms to industry wage variation $\left(\operatorname{cov}\left(\widehat{\kappa}^{p}, \widehat{\kappa}^{f}\right) / \operatorname{var}\left(\widehat{\kappa}^{* *}\right)\right)$.

We contrast the extent to which differences in wage policies across individual firms explain the total variance in wage rates $\left(\widehat{\nu_{f}}\right)$ with the importance of firms in explaining industry wage differences $\left(\widehat{\mu_{f}}\right)$. This contrast is important because it allows discussing the extent to which high wage firms or high wage workers are specific to industries. For instance, suppose that each industry is a random sample of the underlying population of firms and workers. This implies that the underlying differences in remuneration across firms and workers are completely eliminated at the industry level - every industry is characterized by the same average unobserved worker skill and by the same average wage policy. In contrast, suppose that there are only two industries. The first industry contains all high-wage firms, the second industry contains only low-wage firms. Industries sample from the underlying population of workers at random. In this economy, firms will contribute $100 \%$ of the total variance in industry wage differentials since average worker skill is orthogonal to industry. Thus, contrasting the importance of firms at the individual level and at the firm level allows important insights with respect to how well industries proxy for the underlying population of firms and workers.

Comparing $\widehat{\nu_{f}}$ with $\widehat{\mu_{f}}$ reveals that there are two reasons for different importance of firms at

\footnotetext{
${ }^{11}$ But note that in most cases, a test that is based only on wage information does not have sufficient power to discriminate between competing theories.

${ }^{12}$ The industry specific firm effect (person effect) is obtained by a regression of the firm effect (person effect) on the observable characteristics $x_{i t}$ and the industry dummies. Intuitively, the industry specific firm effect $\widehat{\kappa}^{f}$ captures cross industry differences in firms' wage policies in a hypothetical world without differences in observable characteristics $x_{i t}$. The industry specific person effect $\widehat{\kappa}^{p}$ captures cross industry differences in workers' productive skills in a hypothetical world without differences in observable characteristics $x_{i t}$.
} 
the individual and at the industry level. First, the relative variance of the firm's contribution at the individual level and at the aggregate level can differ. Second, differential sorting of individuals across firms can explain why firms contribute more strongly at the aggregate level compared to the individual level even if relative variances are constant.

\subsection{Endogenous Mobility: Example}

We discuss how the nature of interfirm mobility affects estimates of $\phi$, and $\gamma$ and thus the relative importance of firms and workers in wage setting. In order to discuss why job mobility might affect the estimated worker and firm effects consider the following example. Suppose, for simplicity, homogenous individuals with respect to $x_{i t}$ and $\theta_{i}$ (these parameters are normalized to 0 ), and firms which differ only with respect to a time-invariant wage component $\phi_{j}$. Additionally suppose that there are just two points of time 0 and $1^{13}$ and that at time 0 there is just one firm with index 1 . The wage rate at time 0 is $y_{i 0}=\phi_{1}+\epsilon_{i 0}$, where $\epsilon_{i 0}$ reflects the random component of productivity of worker $i$ at time 0 . At time 1, all workers get an outside wage offer $y_{i 1}^{*}=\phi_{j}+\epsilon_{i 1}^{*}, j=2 \ldots J$. Workers are assumed to earn the wage they earned at time 0 if they decide to stay with their employer at time $1 .{ }^{14}$ All random shocks to productivity are i.i.d. If we abstract from additional amenities or disamenities of jobs, workers will move from employer 1 to employer $j$ if the outside wage offer exceeds the inside wage offer

$$
\phi_{j}+\epsilon_{i 1}^{*} \geq \phi_{1}+\epsilon_{i 0}
$$

Observed wage rates at time 1 are then given by $y_{i 1}=I\left(\phi_{j}+\epsilon_{i 1}^{*} \geq \phi_{1}+\epsilon_{i 0}\right) y_{i 1}^{*}+\left(1-I\left(\phi_{j}+\epsilon_{i 1}^{*} \geq\right.\right.$ $\left.\left.\phi_{1}+\epsilon_{i 0}\right)\right) y_{i 0}$ where $I(A)$ is the indicator function taking the value 1 if $A$ is true and 0 otherwise. The least squares estimator identifies the effect of firm $j$ on wages relative to firm 1 based on the expected wage change for movers from firm 1 to firm $j^{15}$

$$
\begin{array}{r}
E\left(y_{i 1}-y_{i 0} \mid J(i, 1)=j, J(i, 0)=1\right)=\phi_{j}-\phi_{1}+ \\
+E\left(\epsilon_{i 1}^{*}-\epsilon_{i 0} \mid \epsilon_{i 1}^{*}-\epsilon_{i 0} \geq-\left(\phi_{j}-\phi_{1}\right)\right)
\end{array}
$$

This shows first, that the estimator of the firm effect is biased upward since $E\left(\epsilon_{i 1}^{*}-\epsilon_{i 0} \mid \epsilon_{i 1}^{*}-\epsilon_{i 0} \geq\right.$ $\left.-\left(\phi_{j}-\phi_{1}\right)\right)>0$. Second, the smaller the true relative firm effect $\left(\phi_{j}-\phi_{1}\right)$ is, the stronger is the upward bias in the estimated firm effect. As a result, the variance in the firm effect identified with JTJ transitions tends to be smaller than the variance in the true firm effects thereby

\footnotetext{
${ }^{13} \mathrm{As}$ in our dataset we use the concept of points in time where we observe the individuals. Thus between time 0 and 1 there are several days where we do not observe the individuals but at time 1 we have information on what happened between time 0 and 1 .

${ }^{14}$ This assumption is made for simplicity. All results hold at the qualitative level if the wage rate at time 1 is a new random draw from the firm specific wage distribution.

${ }^{15}$ See Abowd, Creecy, and Kramarz (2002) for a more exhaustive treatment of identification of worker and firm effects.
} 
reducing the explanatory power of firms in wage determination.

In order to study JUJ mobility, suppose that all workers are laid off between time 0 and 1 and become unemployed earning unemployment benefits given by $b y_{i 0}$ with $b$ denoting the unemployment benefit replacement rate. As before, individuals receive an outside wage offer at time $1 y_{i 1}^{*}=\phi_{j}+\epsilon_{i 1}^{*}$. Assuming that individuals place zero value on leisure, individuals will accept this wage offer if it exceeds unemployment benefits, i.e.

$$
\phi_{j}+\epsilon_{i 1}^{*} \geq b\left(\phi_{1}+\epsilon_{i 0}\right)
$$

Observed wages at time 1 are given by $y_{i 1}=I\left(\phi_{j}+\epsilon_{i 1}^{*} \geq b\left(\phi_{1}+\epsilon_{i 0}\right)\right) y_{i 1}^{*}$. Note that at time 1 only a subset of all individuals who were present at time 0 are observed in employment. The mass of this set depends on the probability that wage offers exceed unemployment benefits. This probability is high if unemployment benefits are low.

The least squares estimator of the effect of firm $j$ relative to firm 1 focuses on wage changes of individuals who have experienced unemployment between time 0 and 1 . This estimator identifies

$$
\begin{array}{r}
E\left(y_{i 1}-y_{i 0} \mid J(i, 1)=j, J(i, 0)=1\right)=\phi_{j}-\phi_{1}+ \\
+E\left(\epsilon_{i 1}^{*}-\epsilon_{i 0} \mid \epsilon_{i 1}^{*}-\epsilon_{i 0} \geq-\left(\phi_{j}-\phi_{1}\right)-(1-b)\left(\phi_{1}+\epsilon_{i 0}\right)\right)
\end{array}
$$

This shows that, again, the estimated relative firm effect is affected by an upward bias. However, there are two crucial differences between the JUJ identification strategy and the JTJ identification strategy. First, the average bias is lower since the second term in the selection condition is strictly negative, i.e. $-(1-b)\left(\phi_{1}+\epsilon_{i 0}\right)<0$. This term reflects the fact that JUJ movers are less choosy in accepting wage offers than JTJ movers in the sense that the previous wage $\phi_{1}+\epsilon_{i 0}$ reduces the bias in the effect of firm $j$ relative to firm 1 . The extent to which this second term reduces the bias in estimating the relative firm effect depends monotonically on the replacement rate $b$. Thus, the bias is largest if $b=1$ (JTJ case) and it is zero when $b$ is zero (the case without unemployment insurance), because the conditioning event simply states that the wage offer must be positive $\left(\phi_{j}+\epsilon_{i 1}^{*} \geq 0\right)$. Second, depending on the actual institutional framework, wage offers below the unemployment benefit can be quite rare. For instance, the ratio of the minimum wage to the mean wage was 0.62 and, in 1990, the replacement ratio was $40.4 \%$ for the median income earner. ${ }^{16}$ Furthermore, because unemployment benefits are capped from above in Austria, even workers who have earned a high wage prior to unemployment are likely to earn less than the minimum wage while on unemployment benefits. Thus, if $\phi_{j}+\epsilon_{i 1}^{*} \geq$ $\underline{y}>b\left(\phi_{1}+\epsilon_{i 0}\right)$ with $\underline{y}$ the minimum wage, the bias in the JUJ estimator vanishes completely because the constraint that the wage offer exceeds unemployment benefits (7) is not binding.

This simple example illustrates that the potential bias from relying on JTJ mobility in iden-

\footnotetext{
${ }^{16}$ Note that the relative magnitude of UI and minimum wages in Austria is in contrast to the situation in France but more in line with the U.S. institutions.
} 
tifying the contribution of firms to wage rates is potentially important and that this bias is correlated negatively with the magnitude of the relative firm effect. In contrast, identification based on JUJ mobility tends to be affected less strongly by endogenous mobility bias. It is important to keep in mind that this simple example is meant to illustrate the potential implications of JTJ relative to JUJ mobility. It is obvious that the example abstracts from a number of important features encountered on actual labor markets such as differences across workers in observed time-varying characteristics, unobserved time-constant characteristics, the existence of multiple firms at time 0 , and simultaneous occurrence of JTJ and JUJ mobility. Nevertheless, it is unlikely that the insight regarding the relative bias due to JTJ and JUJ mobility is altered at the qualitative level.

We discuss the extent to which inter-firm mobility affects the importance of firms in wage determination by contrasting two samples of movers. The first sample considers workers who have moved between employers at least once and always did so directly from job-to-job - the JTJ sample. The second sample is identical to the first sub-sample with the exception that workers have experienced a spell of unemployment between jobs - the JUJ sample. We then apply the wage decomposition algorithm, separately, to the JTJ sample and to the JUJ sample. This gives two sets of parameter estimates, the first being identified solely based on job-to-job mobility, the second being based, exclusively, on job-unemployment-job mobility. This means that we can assess the relevance of inter-firm mobility for the wage decomposition (1) by contrasting the importance of firms in the JTJ sample to the importance of firms in the JUJ sample (both at the individual and at the industry level). The difference in the two statistics provides information on the extent to which the importance of firms in wage setting is sensitive due to the fact that identification relies fully on JTJ mobility (JTJ sample) as opposed to identification ruling out JTJ mobility completely (JUJ sample). Thus, this comparison is informative on the maximum extent to which endogenous mobility affects the importance of firms in wage determination.

\section{Data}

We use Austrian social security data (ASSD) to study the relevance of firms in wage setting and discuss the role of inter-firm mobility. This data set is ideally suited to study the issue of job mobility in determining firm wage components as it allows us to trace the individuals' complete earnings and employment history. Not only sequences of jobs but also intermediate spells of unemployment can be observed. Our sample covers $25 \%$ of all individuals who were ever employed in the private sector in Austria on October 10th in the period between 1990 and 1997. This data contains information on employment (blue/white collar, tenure, experience), earnings, and the identification number of the employer. In addition, there is information on gender and date of birth for each individual. Incomplete data on nationality and education can be inferred from the Austrian unemployment register for those individuals who ever enter 
unemployment in the period from 1986 until 1997.

The analysis is restricted to male employees between 25 years and 55 years for two reasons. First, the data set does not provide information on working hours. At 25 years of age, most individuals have completed their education and are able to work full-time. ${ }^{17}$ Second, early retirement starts at age 60 (for males) and 55 (for females). In order to rule out early retirement effects we focus on an age group that is below the early retirement age. ${ }^{18}$ We focus only on those employees who were working and focus on the job with the highest earnings in the case of multiple jobs. ${ }^{19}$ Using these selection criteria our data-set includes 2,090,483 observation of 378,244 different persons and 103,346 firms.

We discuss the effect of identifying the wage decomposition based on JTJ mobility as opposed to JUJ mobility. The impact of JTJ mobility relative to JUJ mobility can be studied in the following two sub-samples

- The JUJ sample contains all individuals who changed jobs at least once and always experienced a spell of unemployment between successive jobs. A job change occurs if the employer in one year is different from the employer in the preceding year. ${ }^{20}$ The idea is that, in the JUJ sample, the wage rate in the previous job is likely to play a minor role in determining the wage rate in the new job. The JUJ sample contains 299,310 observations of 54,991 different individuals and 51,630 different firms.

- The JTJ sample contains all individuals who changed their job at least once but never through unemployment. The idea is that, in the JTJ sample, job mobility is driven by the new wage rate exceeding the wage rate in the previous job. For instance workers who happen to be matched with a high wage employer will only be induced to change to a new employer if that employer offers an even higher wage rate. Thus this sample likely to contain endogenous mobility. The JTJ sample contains 441,900 observations of 68,678 different individuals and 54,586 firms.

- By construction, no individual shows up in both, the JTJ and the JUJ sample. However, 21,352 firms are common to both sub-samples. We will use this overlap in the data to answer our second question, the effect of interfirm mobility.

Austrian labor law forces employers to notify workers of a pending layoff three months in advance. Since we can not infer from the data whether or not the worker is laid off or quits, we

\footnotetext{
${ }^{17}$ According to Statistics Austria, only $2.36 \%$ of all male employees aged 25 to 54 are part-time workers, but $25.0 \%$ of all employed women work part-time.

${ }^{18}$ Note that basically due to disability insurance already about $20 \%$ of all men have terminated their working career at the age of 55 .

${ }^{19}$ Multiple job holders make up less than $1 \%$ of the dataset.

${ }^{20}$ This classification means that if an employee changed within a year away from his old employer and than back again, this would not count as a job change. Also so called recalls (from unemployment) do not count as job changes.
} 
possibly allocate some workers into the JTJ sample who were actually faced with a permanent layoff. However, note that such mis-allocation will tend to bias our contrast of the JUJ sample with the JTJ sample towards finding a zero effect. Thus, our results can be understood as giving a lower bound on the actual relevance of inter-firm mobility. Moreover, contrasting the JTJ with the JUJ sample can, potentially, be difficult since this contrast not only reflects interfirm mobility but also different composition of the JUJ and the JTJ sample. We address the relevance of this concern in section 4 .

\subsection{Construction of Main Variables}

This sub-section describes the main variables used in the following empirical analysis. We concentrate on those variables which needed to be constructed.

The dataset contains information on annual earnings. Because we also know the number of days worked within a year, the dependent variable is the log of deflated income per day worked, the 'daily wage'. ${ }^{21}$ Because there is an upper contribution limit to the state pension system in Austria, annual earnings are top coded. Top coding affects roughly $15 \%$ of all income information. In order to address the top-coding problem, we construct a cluster of 1,440 cells based on age, experience, place of work, blue collar or white collar and year. Then, we estimate a tobit regression for each cell with log wage as the dependent variable and a constant as the only regressor. This yields the moments of the distribution of a censored normal variable that fits the wage distribution best within each cell. With this information we can impute, for all individuals with a wage above the limit, the daily wage by the expectation of the upper tail of the truncated distribution.

We define previous work experience and job tenure as the number of days actually worked since 1972 instead of using potential labor force experience. To allow for a flexible experience profile we recode work experience into eight different categories $(0,1,2-3,4-5,6-8,9-12,13-17$, $18+$ years of experience). Because of the known insurance type we can distinguish between blue and white collar workers. ${ }^{22}$ 
Table 1: Descriptive Statistics of Selected Variables

\begin{tabular}{lccc}
\hline \hline & A. Main Sample & B. JTJ Sample & C. JUJ Sample \\
\hline Wage rate (natural logarithm) & 6.783 & 6.822 & 6.562 \\
& $(0.473)$ & $(0.524)$ & $(0.375)$ \\
Work experience (years) & 14.771 & 14.421 & 11.661 \\
& $(6.676)$ & $(6.765)$ & $(5.587)$ \\
Tenure (years) & 6.197 & 4.195 & 2.196 \\
& $(6.831)$ & $(5.400)$ & $(3.526)$ \\
Age (years) & & & \\
& 37.845 & 36.974 & 35.958 \\
Blue Collar & $(8.641)$ & $(8.126)$ & $(7.730)$ \\
& & & \\
& 0.563 & 0.466 & 0.762 \\
No. of Workers & $(0.496)$ & $(0.499)$ & $(0.426)$ \\
No. of Firms & & 68,678 & 54,991 \\
No. of Obs. & 378,244 & 54,586 & 51,630 \\
\hline \hline
\end{tabular}

Source: ASSD, own calculations.

Notes: Standard deviation in parentheses. JTJ sample includes all movers without unemployment between two jobs; JUJ sample includes all movers with a spell of unemployment between every job.

\subsection{Descriptive Statistics}

Table 1 provides the means and standard deviations of the relevant variables. Comparing the JTJ sample and the JUJ sample in table 1, we note that the average worker in the JTJ sample earns a higher wage than the average worker in the JUJ sample. On the average individuals in the JTJ sample have more work experience and longer tenure than individuals in the JUJ sample and are slightly older. Additionally the JTJ worker is less likely to hold a blue collar position. Because tenure is job specific the average tenure must be lower than in the main sample, where fewer job changes occur. These descriptive statistics show that those who were never unemployed have better observable characteristics on average and therefore they earn higher wages.

Table 2 reports average changes in the log of daily earnings between consecutive years within persons. In the main dataset, there is a total of 1,712,239 wage change observations, i.e. one less for each person $(1,712,239=2,090,483-378,244)$. The first row in table 2 shows that average wage growth is about $2.2 \%$ in the main sample, slightly larger $(3.1 \%)$ in the sample that is restricted

\footnotetext{
${ }^{21}$ Recall that no information on hours worked is available. However, because the analysis is restricted to males aged 25 to 55 almost all individuals are full-time workers. Thus, our wage information does not capture the price of labor because work input may differ along the intensity and time dimension. Nevertheless, we use the term 'price of labor' synonymously with the estimated firm effect in order to distinguish between the wage rate that reflects both worker and firm determinants of wages from the firm effect that only reflects the latter.

${ }^{22}$ The dataset provides information on years of schooling only for those individuals who have been unemployed at least once in the period from 1986 until 1997. Therefore, we do not use information on education to separate the worker effect into an observable and an unobserved component. The appendix provides this decomposition in order to compare our results to the literature. Note that discarding information on education does not affect the primary purpose of this paper - identification of the relevance of firms in wage setting.
} 
Table 2: Descriptive Statistics: Log Wage Changes

\begin{tabular}{lccc}
\hline \hline & A. Main Sample & B. JTJ Sample & C. JUJ Sample \\
\hline Total & 0.022 & 0.031 & 0.008 \\
& $(0.184)$ & $(0.239)$ & $(0.232)$ \\
Stayer & 0.024 & 0.026 & 0.023 \\
& $(0.119)$ & $(0.135)$ & $(0.116)$ \\
JTJ Transitions & 0.050 & 0.044 & - \\
& $(0.403)$ & $(0.422)$ & - \\
JUJ Transitions & -0.031 & - & -0.023 \\
& $(0.374)$ & - & $0.367)$ \\
Share of JTJ Transitions & 51.62 & 100.00 & 0.00 \\
No. of Obs. & $1,712,239$ & 373,222 & 244,319 \\
\hline \hline
\end{tabular}

Source: ASSD, own calculations.

Notes: Standard deviation in parentheses. JUJ is a job-unemployment-new job transition, JTJ is a job new job transition. See notes table 1 for a definition of the sub-samples.

to individuals who are observed to move between firms without entering unemployment (JTJ sample), and wage growth is almost zero $(0.8 \%)$ in the dataset containing individuals who always change via unemployment (JUJ sample). Interestingly, the second row in table 2 shows that these differences in average wage growth are not due to differences in wage growth for stayers. Thus, both sub-datasets are comparable to the main dataset in terms of stayer wage growth. The third and the fourth row report average wage changes for JTJ transitions and JUJ transitions, respectively. A striking picture emerges. Whereas wage growth is about twice as high for individuals moving directly between firms compared to stayers ( $5.0 \%$ vs $2.4 \%$ ), average wage growth is significantly negative for JUJ transitions $(-3.1 \%)$ in the main dataset. Results for the sub-datasets show that the average JTJ transition in the JTJ dataset commands a similar wage increase as the average JTJ transition in the main dataset (4.4\% vs $5.0 \%$ ). A similar conclusion holds for the average JUJ transition $(-2.3 \%$ vs $-3.1 \%)$. These results suggest that contrasting the wage decomposition obtained in the JTJ sample with the decomposition obtained in the JUJ sample is informative on the extent to which a wage decomposition is affected by JTJ mobility. ${ }^{23}$ The idea is that the wage decomposition in the JTJ dataset relies exclusively on JTJ transitions in identifying the firms' wage policy. In contrast, in the JUJ dataset, the firms' wage policy is identified by transitions which are more in line with the underlying experiment that defines the wage policy, i.e. with the experiment of placing workers into firms at random.

\subsection{Industry Wage Differentials in Austria}

Regressing the log wage rate on industry affiliation of the employer and experience, age, tenure (and the squared of these), education, year dummies and blue collar status yields the industry

\footnotetext{
${ }^{23}$ Note that this contrast needs to account for the fact that workers as well as firms differ across the sub-samples. We discuss a way to account for selectivity in the following section.
} 
wage differentials reported in table $3 .^{24}$ All estimated industry wage differentials are highly significant. For example wages in the mining, metal, printing, building materials, or air traffic industry are higher than the average wage while they are lower in most service sector industries. The adjusted ${ }^{25}$ standard deviation of the industry wage differential shows the overall variability of the industry effect. It is considerably larger than the one reported in Krueger and Summers (1988) for the U.S.

In the second column of table 3, we reproduce the U.S. industry wage differentials reported in Krueger and Summers (1988). Because of some differences in the industry classifications ${ }^{26}$ it is not possible to provide an exact comparison. Thus, we concentrate on the sub-set of KruegerSummer industries which we could match with the corresponding industry in Austria (column 2 of table 3). The correlation between industry differentials in Austria with those in the U.S. is quite strong (0.532). This suggests that not only are industry wage differentials important in Austria in terms of wage dispersion but it is also true that, on average, high wage industries in the U.S. are also high wage industries in Austria.

Table 3: Estimation of the Inter-Industry Differentials

\begin{tabular}{lrrlrc}
\hline \hline \multirow{2}{*}{ Main Sample } & & \multicolumn{2}{c}{ Krueger and Summers 1979 } \\
& Coef. & $(\mathrm{SE})$ & Industry & Coef. & $(\mathrm{SE})$ \\
& & & & & \\
\hline Agriculture and Fishing & -0.252 & $(0.007)$ & & & \\
Forestry & -0.061 & $(0.007)$ & & \\
Energy & 0.171 & $(0.007)$ & Public Utilities & 0.068 & $(0.028)$ \\
Water & -0.025 & $(0.015)$ & & & \\
Mining & 0.196 & $(0.007)$ & Mining & 0.263 & $(0.031)$ \\
Food, Drink, and Tobacco & 0.065 & $(0.007)$ & Food & 0.019 & $(0.026)$ \\
& & & Tobacco & -0.04 & $(0.156)$ \\
Textiles & -0.046 & $(0.007)$ & Textiles & -0.034 & $(0.156)$ \\
Apparel & -0.168 & $(0.008)$ & Apparel & -0.132 & $(0.030)$ \\
Leather & -0.160 & $(0.008)$ & Leather & -0.233 & $(0.051)$ \\
Wood & -0.046 & $(0.007)$ & Lumber & -0.35 & $(0.035)$ \\
& & & Furniture & -0.12 & $(0.036)$ \\
Music Instr. and Toys & -0.020 & $(0.008)$ & Instruments & 0.137 & $(0.040)$ \\
Paper & 0.174 & $(0.007)$ & Paper & 0.088 & $(0.033)$ \\
Printing & 0.198 & $(0.007)$ & Printing & 0.039 & $(0.028)$ \\
Rubber and Chem. & 0.134 & $(0.007)$ & Rubber & 0.023 & $(0.036)$ \\
& & & Chemical & 0.148 & $(0.029)$ \\
Building Materials & 0.150 & $(0.007)$ & Stone, Clay and Glass & 0.052 & $(0.034)$ \\
Metals & 0.145 & $(0.007)$ & Primary Metals & 0.114 & $(0.026)$ \\
& 0.148 & $(0.007)$ & Fabricated Metals & 0.039 & $(0.026)$ \\
Machinery & & & Machinery, excl. Elec. & 0.092 & $(0.022)$ \\
& & & Electrical Machinery & 0.045 & $(0.021)$
\end{tabular}

\footnotetext{
${ }^{24}$ As the data do not contain information on industry affiliation for about $10 \%$ of observations, we construct a hypothetical "Unknown" industry. Reasons for missing industry affiliation include coding errors at data collection.

${ }^{25}$ Following Krueger and Summers (1988) we compute the adjusted standard deviation by using the formula $S D(\kappa) \approx \sqrt{\operatorname{var}(\hat{\kappa})-\sum_{i=1}^{K} \frac{\hat{\sigma}_{i}^{2}}{K}}$. Note that this is the unweighted standard deviation. The weighted SD is 0.117.

${ }^{26}$ Krueger and Summers (1988) use May 1979 CPS data that contains industry classification according to the U.S. census scheme. Our data contains (the Austrian version of) the European industry classification NACE.
} 
Table 3: (continued)

\begin{tabular}{lrrlrl}
\hline \hline & Main Sample & & & \multicolumn{3}{c}{ Krueger and Summers 1979 } \\
Variable & Coef. & $(\mathrm{SE})$ & & Coef. & $(\mathrm{SE})$ \\
& & & & & \\
Electrotechnics & 0.213 & $(0.007)$ & & & \\
Vehicles & 0.041 & $(0.007)$ & Transport Equipment & 0.156 & $(0.021)$ \\
Fine-Mechanics & 0.023 & $(0.007)$ & & & \\
Constructions & 0.099 & $(0.007)$ & Constructions & 0.137 & $(0.016)$ \\
Wholesale Trade & -0.009 & $(0.007)$ & Wholesale Trade & -0.015 & $(0.020)$ \\
Retail Trade & -0.087 & $(0.007)$ & Eating and Drinking & -0.125 & $(0.020)$ \\
& & & Other Retail & -0.093 & $(0.050)$ \\
Accommodation & -0.192 & $(0.007)$ & & & \\
Road Traffic, Railway & -0.031 & $(0.007)$ & Railroad & 0.12 & $(0.037)$ \\
Inland Navigation & 0.120 & $(0.013)$ & & & \\
Air Traffic & 0.206 & $(0.008)$ & & 0.12 & $(0.022)$ \\
Shipping & 0.030 & $(0.007)$ & Other Transport & 0.064 & $(0.027)$ \\
Telecommunication & -0.384 & $(0.008)$ & Communications & -0.063 & $(0.031)$ \\
Banking and Credit & 0.117 & $(0.007)$ & Banking & 0.022 & $(0.027)$ \\
Insurance & 0.002 & $(0.007)$ & Insurance & & \\
Real Estate & 0.052 & $(0.007)$ & & & \\
Cleaning & -0.165 & $(0.007)$ & & -0.078 & $(0.019)$ \\
Arts and Entertainment & 0.027 & $(0.007)$ & Entertainment & 0.063 & $(0.018)$ \\
Health & -0.062 & $(0.007)$ & Hospitals & & \\
& & & Medical Services & -0.039 & $(0.022)$ \\
& & & Welfare Services & -0.19 & $(0.032)$ \\
Education and Research & -0.345 & $(0.007)$ & Education Services & -0.185 & $(0.019)$ \\
Regional Corporation & -0.152 & $(0.007)$ & & & \\
Building Maintenance & -0.140 & $(0.013)$ & & & \\
Unknown & 0.033 & $(0.007)$ & & & \\
& & & & & \\
\hline No. of Obs. & $2,090,483$ & & & & \\
SD & 0.151 & & & & \\
\hline \hline
\end{tabular}

Source: ASSD, own calculations. Estimation for 1979 by Krueger and Summers (1988) (Table II)

Notes: The pooled regression is based on the main sample. Other explanatory variables are education, no education dummy, experience, age, tenure, tenure ${ }^{2}$, year dummies, Vienna dummy, big city dummy, and blue collar dummy. Only those Industries (May CPS classification) are shown in the latter row which are more or less comparable to the industry classification in Austria. The standard deviation is the same as shown in Krueger and Summers (1988).

\section{Results}

In this section we present and discuss the results obtained from estimating equation (1). ${ }^{27}$ We decompose the individual wage rate and the industry wage rate into their components as described in section 2.2 and calculate the extent to which each contributes to the variance in wage rates. In the second part we use the two subsamples to discuss how the nature of inter-firm mobility affects the contribution of workers and firms to the variance in wage rates.

\footnotetext{
${ }^{27}$ See table (10) in the Appendix for the regression output.
} 


\subsection{How Important are Firms in Wage Setting?}

Table 4 reports the extent to which observed worker characteristics, unobserved worker characteristics, firms, and time-varying but unobserved factors contribute to the variance in individual wages in the main dataset. Results indicate that more than $59 \%$ of the variance in wage rates is due to differences in unobserved, constant skills across workers. ${ }^{28}$ In comparison, the contribution of differences in firms to the individual wage structure is much lower. The contribution of firms' wage policies to the variance in wages is roughly $26 \%$. Time-varying observable characteristics such as work experience, blue collar, and time dummies contribute $8 \%$ and unobservable characteristics contribute about $5 \%$ to the variance in wages.

Table 4: The Components of Individual Wages

\begin{tabular}{lrrrrr}
\hline \hline & \multicolumn{5}{c}{ Covariance with } \\
& Tontribution & Firm effect $(\widehat{\psi})$ & Worker effect $(\widehat{\theta})$ & Obs. char. $(X \widehat{\beta})$ & Error Term $(\widehat{\epsilon})$ \\
& & $(2)$ & $(3)$ & & $(5)$ \\
\hline Firm effect $(\widehat{\psi})$ & 26.63 & 37.04 & -11.24 & 0.83 & 0.00 \\
Worker effect $(\widehat{\theta})$ & 59.74 & -11.24 & 66.25 & 4.72 & 0.00 \\
Obs. char. $(X \widehat{\beta})$ & 8.65 & 0.83 & 4.72 & 3.10 & 0.00 \\
Error term $(\widehat{\epsilon})$ & 4.98 & 0.00 & 0.00 & 0.00 & 4.98 \\
Total & 100.00 & 26.63 & 59.74 & 8.65 & 4.98 \\
\hline \hline
\end{tabular}

Source: ASSD, own calculations.

Notes: Variance of log individual wage rates is 0.2238 .

Columns (2) to (5) in table 4 decompose the total contribution of firms. The variance in firm effects is almost $37 \%$ of the overall variance in wage rates. The covariance between worker and firm effects is negative and is on the order of $11 \%$ of the overall variance in wage rates. The covariance between the firm effect and time-varying worker characteristics is very small, and the covariance between firm effects and the estimated error term is zero as required for the least squares solution. The second row in table 4 reports the corresponding statistics for the total worker contribution to the variance in wage rates. This row shows that workers are more important than firms in contributing to wages for two reasons. First, the variance in worker effects is impressive amounting to more than $66 \%$ of the overall variance in wages. Second, there is a positive correlation between worker effects and time-varying observable worker characteristics amounting to almost $5 \%$ of overall variance. Again, estimated worker effects are orthogonal to estimated errors.

Our findings motivate a specific way of thinking about the role of firms in setting wages.

\footnotetext{
${ }^{28}$ See Appendix for the correlation structure between estimated wage components and a comparison thereof with the literature. The dominant role of workers in wage determination is due, in part, to the fact that we report the total worker effect that reflects both differences in education as well as 'truly' unobservable differences in productivity across workers. In the further analysis we do not decompose the total worker effect into a part due to education and a second part due to unobservables because information on education is not available for all workers.
} 
A candidate theory must rationalize moderate differences in firm wage policies combined with negative sorting of workers across firms at the individual level. For instance, the theory of equalizing differences puts forward the idea that firms' wage policies reflect remuneration for dis-amenities, risk of injury or death or other job characteristics (Rosen (1986)). In this view, the firm's contribution to the wage rate is a risk premium. Since technology differs across firms, firm wage policies differ. Negative sorting of workers across firms occurs due to the income effect - high wage earners 'purchase' safer jobs (Hwang, Reed, and Hubbard (1992)).

In turning to the importance of firms at the industry level, figure 1 then plots the raw industry effect in the main sample $\widehat{\kappa}_{k}^{* *}$ against the industry specific firm effect $\widehat{\kappa}_{k}^{f}$ (figure $1(\mathrm{a})$ ) and the industry specific person effect $\widehat{\kappa}_{k}^{p}$ (figure $1(\mathrm{~b})$ ), respectively (the sub-script $k$ indexes industries and runs from 1 to 39). Figure 1 reveals a striking result. The industry wage differentials from a cross section are very closely related to the typical wage policy of firms in the industry (employment weighted ${ }^{29}$ correlation coefficient $\rho=0.941$; plot a). In comparison, the correlation between the raw industry wage differentials and the industry average quality of workers is less strong (weighted correlation coefficient $\rho=0.707$; plot $\mathrm{b}$ ).

Table 5: The Components of Wages Across Industries

\begin{tabular}{lrrr}
\hline \hline & Total & \multicolumn{2}{c}{ Covariance with } \\
& Contribution & Firm component $\left(\widehat{\kappa}^{f}\right)$ & Worker component $\left(\widehat{\kappa}^{p}\right)$ \\
& $(1)$ & $(2)$ & $(3)$ \\
\hline Firm component $\left(\widehat{\kappa}^{f}\right)$ & & & 12.45 \\
Worker component $\left(\widehat{\kappa}^{p}\right)$ & 74.23 & 61.78 & 13.32 \\
Total & 25.77 & 12.45 & 25.77 \\
\hline \hline
\end{tabular}

Source: ASSD, own calculations.

Notes: Variance of the employment weighted log industry wage differential is 0.0137 .

Table 5 presents the relative importance of firms and workers in the inter-industry structure of wages. ${ }^{30}$ The first column in table 5 shows that, in contrast to results at the individual level, industry wage differentials reflect very strongly differences in the wage policies of firms across industries. The covariance between the typical wage policy of an industry with the industry wage differential accounts for more than $74 \%$ of the total variance in the industry wage differentials. In contrast, differences in the skills of the typical worker between industries account for less than $26 \%$ of the variance in industry wage differentials. This suggests, on one hand, that there

\footnotetext{
${ }^{29}$ We report weighted results because industries differ strongly with respect to employment. Weighted results concentrate on large industries. Unweighted results are very similar to weighted results. In fact, unweighted results imply stronger relevance of endogenous mobility regarding the importance of firms in the industry wage structure. Unweighted results are available from the authors upon request.

${ }^{30}$ Even though the correlation between the raw industry effect in the main sample $\widehat{\kappa}_{M}^{* *}$ with the sum of the respective worker $\left(\widehat{\kappa}_{M}^{p}\right)$ and firm $\left(\widehat{\kappa}_{M}^{f}\right)$ component exceeds 0.99 , the decomposition was not fulfilled algebraically. Thus, in order to ensure a decomposition that adds up to $100 \%$, we report results based on a proxy of the raw industry wage differentials, the sum of the respective worker and firm components, i.e. $\widehat{\kappa}_{M}^{* * s} \equiv \widehat{\kappa}_{M}^{p}+\widehat{\kappa}_{M}^{f}$. Results are not sensitive to using the actual or the adjusted raw industry wage differential.
} 
are systematic differences in firms' wage policies across industries and, on the other hand, that worker sorting across industries is much less important.

Columns (2) and (3) in table 5 decompose total contribution of firms to the inter-industry wage structure. Across industries, average firm wage policies vary very strongly relative to the overall variance of the industry wage structure. The inter-industry firm wage structure accounts for more than $61 \%$ of the overall variance. In contrast, the variance in remuneration of the average worker across industries is about $13 \%$ of total variance. Thus, workers differ much less across industries than firms. Third, the correlation between the typical wage policy in the industry with compensation for the typical worker is positive and amounts to $12 \%$ of total variance.

Contrasting the importance of firms for wages across individuals and for wages across industries provides a striking result. Firms are much more important in determining the inter-industry wage structure than wage differentials across individuals. Tables 4 and 5 show that this result is due to the fact that both the relative variance in the firm's contribution and the covariance with the worker's contribution are larger at the industry level rather than at the firm level. Larger relative variance of firm's contribution suggests that the industry category very much groups similar firms within industries rather than across industries (in comparison with workers). Larger covariance indicates that better paying industries tend to attract workers who are more productive.

The finding that raw industry differentials reflect primarily unobserved differences in firms' wage policies rather than the differences in unobserved skills of workers across industries stands in contrast to the literature. For instance, Abowd, Kramarz, and Margolis (1999b) find that the raw industry wage differentials are virtually orthogonal to the firm component and very strongly positively correlated with the worker component in France. The result is different for the U.S. with firms contributing a roughly similar fraction to industry wage differentials as workers. (Abowd, Finer, and Kramarz (1999a)) However, note that existing studies that investigated the correlation between raw industry differentials with industry specific person and firm effects have relied either on conditional estimation methods (Abowd, Kramarz, and Margolis (1999b); Abowd, Finer, and Kramarz (1999a)) or did not apply the full statistical model discussed in section 3 (Goux and Maurin (1999)). Abowd, Creecy, and Kramarz (2002) find that conditional estimation methods may not work very well if the set of conditioning variables $\mathrm{Z}$ is limited.

\subsection{Inter-firm Mobility}

Table 6 discusses how the nature of inter-firm mobility affects the contribution of workers and firms to the variance in wage rates. The top left cell in table 6 reports the contribution of firms in the JTJ sample to the variance in wage rates is $26 \%$. In contrast, in the JUJ sample the firms' contribution to the variance in wage rate is much higher; more than $38 \%$ (second cell, top row). Endogenous mobility leads to a reduction of the importance of firms in wage determination by 
as much as 13 percentage points (p.p.) (third cell, top row).

Table 6: Interfirm Mobility and Wages

\begin{tabular}{lrrr}
\hline \hline & \multicolumn{2}{c}{ Effect identified in } & Difference \\
& A. JTJ Sample & B. JUJ Sample & (A-B) \\
& & & \\
\hline Firms effect $(\widehat{\psi})$ & 25.72 & 38.88 & -13.16 \\
Workers effect $(\widehat{\theta})$ & 62.61 & 49.33 & 13.27 \\
Obs. char. $(X \widehat{\beta})$ & 6.95 & 6.57 & 0.38 \\
Error term $(\widehat{\epsilon})$ & 4.72 & 5.22 & -0.50 \\
Total & 100.00 & 100.00 & 0.00 \\
\hline \hline
\end{tabular}

Source: ASSD, own calculations.

Notes: For a description of the samples see note of table (1). Table reports total contributions.

The second row in table 6 reports the impact of endogenous mobility on the estimated importance of workers in wage determination. This analysis shows that, in contrast to conclusions regarding firms, worker effects are more important in wage determination if identification relies on JTJ mobility. The increase in the contribution of workers due to endogenous mobility is identical in absolute value (13 p.p.) to the corresponding effect of endogenous mobility on firms' contribution to the wage rate. Results reported in the third and fourth row show that the contribution of time-varying observed characteristics and the error term remain unaffected by JTJ mobility.

Table 7: Interfirm Mobility and Wages: Details

\begin{tabular}{|c|c|c|c|c|c|}
\hline & \multirow{2}{*}{$\begin{array}{r}\text { Total } \\
\text { Contribution } \\
(1)\end{array}$} & \multicolumn{4}{|c|}{ Covariance with } \\
\hline & & $\begin{array}{r}\text { Firm effect }(\widehat{\psi}) \\
(2)\end{array}$ & $\begin{array}{r}\text { Worker effect }(\widehat{\theta}) \\
(3)\end{array}$ & Obs. char. $(X \widehat{\beta})$ & $\begin{array}{r}\text { Error Term }(\widehat{\epsilon}) \\
(5)\end{array}$ \\
\hline Firm effect $(\widehat{\psi})$ & -13.16 & -12.90 & -0.85 & 0.59 & 0.00 \\
\hline Worker effect $(\widehat{\theta}$ & 13.27 & -0.85 & 14.16 & -0.04 & 0.00 \\
\hline Obs. char. $(X \widehat{\beta})$ & 0.38 & 0.59 & -0.04 & -0.17 & 0.00 \\
\hline Error Term $(\widehat{\epsilon})$ & -0.50 & 0.00 & 0.00 & 0.00 & -0.50 \\
\hline Total & 0.00 & -13.16 & 13.28 & 0.38 & -0.50 \\
\hline
\end{tabular}

Source: ASSD, own calculations.

Notes: Table reports the JTJ-JUJ difference for all Covariance or Variance terms.

Table 7 gives the estimate of the effect of JTJ mobility relative to JUJ mobility on the four separate components of the contribution of firms, workers, observed characteristics, and the error term in wage setting. Note that the four components add up to the total contribution due to endogenous mobility reported in table 6 . The first row in table 7 shows that the reduction in the importance of firms in wage determination is due, primarily, to a strong reduction in the variance of estimated firm wage policies. If firm effects are estimated based on JTJ mobility only, the variance in the price of labor across plants is 13 p.p. lower compared to estimates that are based on JUJ mobility. This is in line with the example discussed in section 2 that argues that individuals moving between employers directly tend to accept only wage offers that exceed 
the wage rate in the previous employer. This leads to a reduction in the variance of estimated firm wage policies relative to the variance in actual firm wage policies. The third cell in the first row of table 7 shows that the covariance between workers and firms tends to decrease slightly due to endogenous mobility (-0.9 p.p.). Endogenous mobility increases slightly the covariance between firm effects and observables (0.6 p.p.).

The second row in table 7 decomposes the contribution of workers to the variance in wages. In contrast to firms, endogenous mobility leads to an increase in the variance of the worker effect relative to the total variance in wages (14 p.p.). There is a small reduction in the covariance between estimated worker effects and the effect of observables on the wage rate (-0.04 p.p.) and no effect of endogenous mobility effect on the covariance between the error term and the worker effect. Thus, as a result, the total contribution of workers to the variance in wages is higher in JTJ mobility than in JUJ mobility estimates by more than 13 p.p.

Table 8: The Importance of Firms in Different Datasets

\begin{tabular}{lccc}
\hline \hline & \multicolumn{2}{c}{ Effect identified in } & Difference \\
& A. JTJ Sample & B. JUJ Sample & (A-B) \\
\hline Effect used in & & & \\
Sub-samples (A: JTJ, B: JUJ) & 25.72 & 38.88 & -13.16 \\
& $(441,900)$ & $(299,310)$ & \\
Common firms sample & 21.91 & 27.49 & -5.58 \\
& $(1,497,943)$ & $(1,497,943)$ & \\
Main sample & 23.09 & 29.10 & -6.10 \\
& $(1,751,218)$ & $(1,721,323)$ & \\
\hline \hline
\end{tabular}

Source: ASSD, own calculations.

Notes: Number of observations in parentheses. Common firms is the sub-sample for which firm effects are identified in both the JTJ sample and the JUJ sample.

Contrasting the JTJ sample with the JUJ sample suffers from an important problem. The fact that workers and firms differ across these two samples may by itself already drive the conclusion that firm effects are more strongly correlated with the wage rate in the JUJ sample than in the JTJ sample. ${ }^{31}$ Table 8 addresses this concern by reporting the importance of

\footnotetext{
${ }^{31} \mathrm{~A}$ second concern is of statistical nature. Perhaps firm effects are identified more precisely in the JUJ dataset relative to the JTJ dataset. However, taking the average number of observations per firm as a proxy for the precision of the estimates, note that firm effects will be estimated more precisely in the JTJ sample (8.1 observations per firm) than in the JUJ sample ( 5.8 observations per firm). Nevertheless, we investigate this issue as follows. First, we pool JTJ observations and JUJ observations. We then allocate the 123,669 workers randomly into two datasets. The first random partition data contains the same number of workers as the original JTJ dataset, and the second random partition dataset contains the same number of workers as the JUJ dataset. Third, we apply the wage decomposition to these two random partition sub-datasets. These datasets are similar to the original JTJ and JUJ dataset with respect to the number of workers, number of firms, and number of observations. In contrast to the original datasets, however, both random partition datasets are characterized by identical shares of JTJ transitions. Results indicate that the importance of firms is $28.12 \%$ in the 'JTJ' random partition data, and $27.54 \%$ in the 'JUJ' random partition data. This suggests that precision of the estimates is not driving results. Furthermore, this analysis shows that the the JTJ and JUJ dataset produce results that are similar to the main sample when they are mixed at random. This means that focusing on sub-set movers does
} 
firms for three different underlying populations of firms and workers. Row 1 reports $\widehat{\nu_{f}}$ for the sub-samples that were used in estimating the firm's contribution. As we have discussed above, contrasting the firm's contribution yields a 13 percentage points lower importance of firms when interfirm mobility of the job-to-job type is used in identification. Because of the different population in both subsamples and thus different overall variance in wages the results may be biased. To avoid this we use the fact that 21,352 firms are identified in both subsamples to construct a subsample which covers all persons who worked in one of these firms. This 'common firms' dataset containing 1.4 million observations contrasts the importance of the same firms for the same workers by transition type used in identification (Row 2 in table 8). Using the firm effect identified in the JTJ sample (column A) and in the JUJ sample (column B) to predict the contribution of the own firm to the wage rate for every worker indicates that the same firm is about 5.6 percentage points less important in explaining the variance in wage rates based on estimates that rely on individuals changing employers without intervening unemployment. ${ }^{32}$ Row 3 )in table 8 uses the same procedure to impute firm's contribution for all workers. This gives valid firm contribution estimates $\left(\widehat{\psi}_{i t}\right)$ for roughly 1.75 million observations in both columns. ${ }^{33}$ When we compare the predictive power of firm effects, results indicate that the firm effects found in the JUJ sample tend to correlate more strongly with the wage rates than the firm effects identified in the JTJ sample. Job changes that occur due to the new employer outbidding the previous employer tend to lead to the conclusion that firms only contribute 23 percent rather than 29 percent to the variance in individual wage rates. Thus, table 8 provides strong evidence that the firms wage setting power is underestimated due to JTJ mobility.

\section{Conclusions}

For a long time period, empirical research on the wage setting power of firms was hampered due to lack of adequate data. Recently, matched employer-employee data has been used to provide the first assessment of the importance of firms in wage setting. Seminal research in Abowd, Kramarz, and Margolis (1999b) suggested that workers rather than firms account for the puzzling strong variance in average wages across industries.

This paper reassess the method developed by Abowd, Kramarz, and Margolis (1999b) for Austria but uses a modified version of the exact method in Abowd, Creecy, and Kramarz (2002). In building on the existing literature, we focus on two unexplored issues. We first contrast the

\footnotetext{
not affect results ex-ante.

${ }^{32}$ Note that when we apply the entire analysis only to the common firms dataset, results are very similar to those reported in the paper. Results are available from the authors upon request. Moreover, when we use firm effects estimated in JTJ mobility and decompose wage rates into person effect, and effects due to X, and error term, JTJ mobility leads to a lower importance of firms and a corresponding increase in the importance of workers in explaining the wage structure.

${ }^{33}$ Since not all firms are included in the JTJ and JUJ sample, respectively, we can not impute the predicted contribution of the current employer to the wage rate for all observations.
} 
extent to which firms are important in explaining wage differences across individuals and across industries. Findings indicate that firms are very important in the inter-industry wage structure rather than in the inter-individual wage structure. Whereas firms account for about three quarters of the differences in wages across industries, only about one quarter of the variance in individual wage rates is due to firms. In explaining this finding, we show that positive sorting of workers across industries and negative sorting of workers across firms explains about one half of the difference in the importance of firms at the industry and at the individual level. Second, we discuss to what extent the two most important, yet fundamentally distinct types of interfirm mobility - job-to-job vs job-unemployment-job - affect the statistical decomposition of the wage rate into a worker effect, a firm effect, and a transitory component. Results indicate that the same firms are much less important in wage setting when identification relies on job-to-job rather than job-unemployment-job mobility.

Our findings document the stylized facts that successful theories of the labor market need to explain. A candidate theory must rationalize moderate differences in firm wage policies combined with negative sorting of workers across firms with a strong role for firms rather than workers in shaping the inter-industry wage structure and positive sorting of workers across industries. Understanding the most important mechanisms that give rise to such differences in wage setting across firms is thus an important topic of future research. 


\section{References}

Abowd, John M., Robert Creecy, and Francis Kramarz (2002): Computing Person and Firm Effects Using Linked Longitudinal Employer-Employee Data. Working paper, Cornell University.

Abowd, John M., Hampton Finer, and Francis Kramarz (1999a): Individual and Firm Heterogeneity in Compensation: An Analysis of Matched Longitudinal Employer and Employee Data for the State of Washington. In: J. Haltiwanger, J. Lane, J. Spletzer, and K. Troske, editors, The Creation and Analysis of Employer-Employee Matched Data, pages 3-24. North-Holland.

Abowd, John M. and Francis Kramarz (1999): The Analysis of Labor Markets Using Matched Employer-Employee Data. In: O. Ashenfelter and D. Card, editors, Handbook of Labor Economics, volume 3B, chapter 26, pages 2629-2710. North-Holland.

Abowd, John M., Francis Kramarz, and David N. Margolis (1999b): High-Wage Workers and High-Wage Firms. Econometrica, 67(2):251-333.

Andrews, Martyn, Thorsten Schank, and Richard Upward (2004): Practical Estimation Methods for Linked Employer-Employee Data. Discussion Paper 03/2004, Institut fuer Arbeitsmarktund Berufsforschung.

Antel, John J. (1991): The Wage Effects of Voluntary Labor Mobility with and without Intervening Unemployment. Industrial and Labor Relations Review, 44(2):299-306.

van den Berg, Gerard J. and Geert Ridder (1998): An Empirical Equilibrium Search Model of the Labor Market. Econometrica, 66(5):1183-1221.

Booth, Alison (1995): The Economics of Trade Unions. Cambridge.

Burdett, Kenneth and Dale T. Mortensen (1998): Wage Differentials, Employer Size, and Unemployment. International Economic Review, 39(2):257-273.

Cahuc, Pierre, Christian Gianella, Dominique Goux, and Andre Zylberberg (2002): Equalizing Wage Differences and Bargaining Power: Evidence from a Panel of French Firms. Discussion Paper 582, IZA.

Carruth, Alan, Bill Collier, and Andy Dickerson (1999): Inter-Industry Wage Differences and Individual Heterogeneity: How Competitive is Wage Setting in the UK? Discussion Paper 99/14, University of Kent, Department of Economics.

Dickens, William T. and Lawrence F. Katz (1987): Inter-Industry Wage Differences and Industry Characteristics. In: Kevin Lang and Jonathan Leonard, editors, Unemployment and the Structure of Labor Markets, chapter 3, pages 48-89. Basil Blackwell Inc. 
Farber, Henry S. (1999): Mobility and stability: the dynamics of job change in labor markets. In: O. Ashenfelter and D. Card, editors, Handbook of Labor Economics, volume 3B, chapter 18, pages 2629-2710. North-Holland.

Gibbons, Robert S. and Lawrence F. Katz (1992): Does Unmeasured Ability Explain InterIndustry Wage Differences? Review of Economic Studies, 59(3):515-535.

Gibbons, Robert S., Lawrence F. Katz, Thomas Lemieux, and Daniel Parent (2002): Comparative Advantage, Learning, and Sectoral Wage Determination. Working Paper 8889, NBER.

Goux, Dominique and Eric Maurin (1999): The Persistence of Inter-Industry Wages Differentials: a Reexamination on Matched Worker-firm Panel Data. Journal of Labor Economics, 17(3):492-533.

Groshen, Erica L. (1991): Sources of Intra-Industry Wage Dispersion: How Much do Employers Matter? The Quarterly Journal of Economics, 106(3):869-884.

Hwang, Hae-Shin, Robert W. Reed, and Carlton Hubbard (1992): Compensating Wage Differentials and Unobserved Productivity. Journal of Political Economy, 100:835-58.

Kahn, Lawrence M. (1998): Collective Bargaining and the Interindustry Wage Structure: International Evidence. Economica, 65(2):507-534.

Kim, Dae Il (1998): Reinterpreting Industry Premiums: Match-Specific Productivity. Journal of Labor Economics, 16(3):479-504.

Krueger, Alan B. and Lawrence H. Summers (1987): Reflections on the Inter-Industry Wage Structure. In: Kevin Lang and Jonathan Leonard, editors, Unemployment and the Structure of Labor Markets, chapter 2, pages 17-47. Basil Blackwell Inc.

Krueger, Alan B. and Lawrence H. Summers (1988): Efficiency Wages and the Inter-Industry Wage Structure. Econometrica, 56(2):259-293.

Manning, Alan (2003): Monopsony in Motion: Imperfect Competition in Labor Markets. Princeton: Princeton University Press.

Margolis, David N. and Kjell G Salvanes (2001): Do Firms Really Share Rents with their Workers ? mimeo, INSEE.

Mortensen, Dale (2003): Wage Dispersion: Why are Similar Workers Paid Differently? MIT Press.

Murphy, Kevin M. and Robert H. Topel (1987): Unemployment, Risk, and Earnings: Testing for Equalizing Wage Differences in the Labor Market. In: Kevin Lang and Jonathan Leonard, editors, Unemployment and the Structure of Labor Markets, chapter 5, pages 103-140. Basil Blackwell Inc. 
Postel-Vinay, Fabien and Jean-Marc Robin (2002): Equilibrium Wage Dispersion with Worker and Employer Heterogeneity. Econometrica, 70(6):2295-2350.

Rosen, Sherwin (1986): The Theory of Equalizing Differences. In: Orley C. Ashenfelter and Richard Layard, editors, Handbook of Labor Economics, volume 1, chapter 12, pages 641692. North Holland.

Shapiro, Carl and Joseph Stiglitz (1984): Equilibrium Unemployment as a Worker Discipline Device. American Economic Review, 75(4):892-893.

Slichter, Sumner H. (1950): Notes on the Structure of Wages. Review of Economics and Statistics, 32(1):80-91.

Topel, Robert H. and Michael P. Ward (1994): Job Mobility and Careers of Young Men. The Quarterly Journal of Economics, 107(2):439-479.

Vainiomki, Jari and Seppo Laaksonen (1995): Inter-Industry Wage Differentials in Finland: Evidence from longitudinal census data for 1975-85. Labour Economics, 2(2):161-173.

Winter-Ebmer, Rudolph (1994): Endogenous Growth, Human Capital, and Industry Wages. Bulletin of Economic Research, 46(4):289-314.

Zweimueller, Josef and Erling Barth (1994): Bargaining Structure, Wage Determination, and Wage Dispersion in 6 OECD Countries. Kyklos, 47(1):81-93. 


\section{A Appendix}

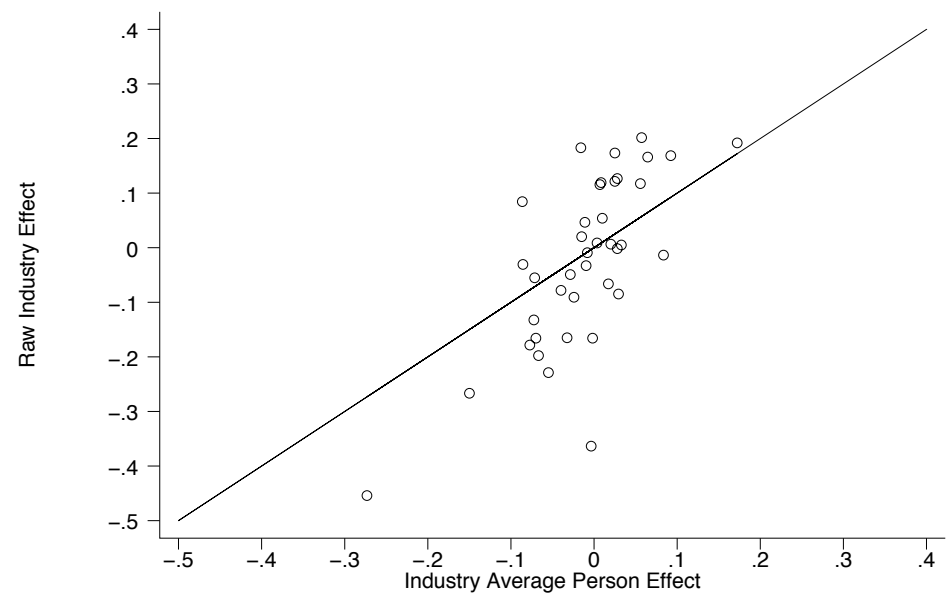

(a)

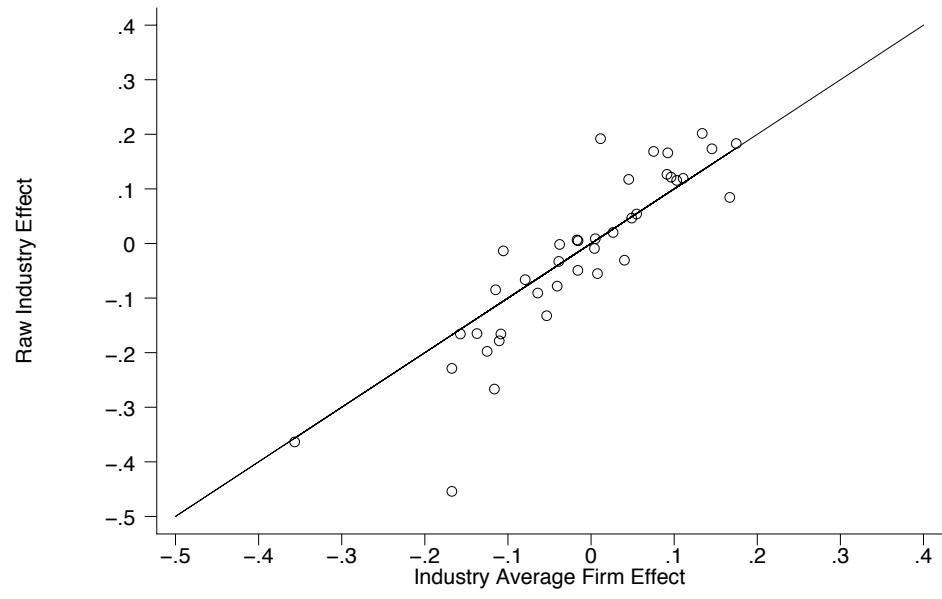

(b)

Figure 1: Scatterplot of the Raw Industry Differential $\widehat{\kappa}^{* *}$ with (a) Firm Component $\widehat{\kappa}^{f}$ (based on $\psi$ ) $(\rho=0.941)$ and (b) Worker component $\widehat{\kappa}^{p}$ (based on $\left.\theta\right)(\rho=0.707)$ 


\section{Estimation method}

The least squares estimator of $\beta, \theta, \phi$, and $\gamma$ solves the following normal equations

$$
\left[\begin{array}{cccc}
X^{\prime} X & X^{\prime} D & X^{\prime} F & X^{\prime} S \\
D^{\prime} X & D^{\prime} D & D^{\prime} F & D^{\prime} S \\
F^{\prime} X & F^{\prime} D & F^{\prime} F & F^{\prime} S \\
S^{\prime} X & S^{\prime} D & S^{\prime} F & S^{\prime} S
\end{array}\right]\left[\begin{array}{l}
\beta \\
\theta \\
\phi \\
\gamma
\end{array}\right]=\left[\begin{array}{c}
X^{\prime} y \\
D^{\prime} y \\
F^{\prime} y \\
S^{\prime} y
\end{array}\right]
$$

It is not possible to invert the cross-product matrix due to the large number of person and firm effects and due to computer memory constraints. ${ }^{34}$

In this paper we apply a modified version of the iterative gradient method proposed in Abowd, Creecy, and Kramarz (2002) to find the solution to the normal equations. The idea of this estimator is simple. Rearranging the system of linear equations in (8) yields

$$
\left[\begin{array}{c}
X^{\prime} X \beta \\
D^{\prime} D \theta \\
F^{\prime} F \phi \\
S^{\prime} S \gamma
\end{array}\right]=\left[\begin{array}{c}
X^{\prime}(y-D \theta-F \phi-S \gamma) \\
D^{\prime}(y-X \beta-F \phi-S \gamma) \\
F^{\prime}(y-X \beta-D \theta-S \gamma) \\
S^{\prime}(y-X \beta-D \theta-F \phi)
\end{array}\right]
$$

These are four blocks of normal equations that yield the required least squares solution given the least squares solution of the remaining three sets of parameters.

The iteration protocol is as follows. Choose starting values $\beta_{0}, \theta_{0}, \phi_{0}$, and $\gamma_{0}$. Let $l$ index iterations. Solve for $\beta_{l}, \theta_{l}, \phi_{l}$, and $\gamma_{l}$ using (9) based on the estimate of the other parameters in iteration $l-1$. This gives the following updating rule

$$
\left[\begin{array}{c}
\beta_{l} \\
\theta_{l} \\
\phi_{l} \\
\gamma_{l}
\end{array}\right]=\left[\begin{array}{c}
{\left[X^{\prime} X\right]^{-1} X^{\prime}\left(y-D \theta_{l-1}-F \phi_{l-1}-S \gamma_{l-1}\right)} \\
{\left[D^{\prime} D\right]^{-1} D^{\prime}\left(y-X \beta_{l}-F \phi_{l-1}-S \gamma_{l-1}\right)} \\
{\left[F^{\prime} F\right]^{-1} F^{\prime}\left(y-X \beta_{l}-D \theta_{l}-S \gamma_{l-1}\right)} \\
{\left[S^{\prime} S\right]^{-1} S^{\prime}\left(y-X \beta_{l}-D \theta_{l}-F \phi_{l}\right)}
\end{array}\right]
$$

Intuitively, the current estimate of $\beta$, for instance, is found by regressing the residuals $y-$ $D \theta_{l-1}-F \phi_{l-1}-S \gamma_{l-1}$ on the matrix $X$.

The algorithm is partially recursive in using the fact that the current value of $\beta$, $\beta_{l}$, can already be used in estimating $\theta_{l}$. In estimating $\phi_{l}$, the current values of $\beta_{l}$ and $\theta_{l}$ are used to form the residuals, etc. The algorithm converges to the true least squares solution because parameter updates are chosen to fulfill the normal equations given the values of the other parameters. We determine convergence to be achieved when the absolute change in the sum of squared errors between iteration $l$ and $l-1$ falls below $1 \cdot 10^{-11}$.

After the least squares solution $\widehat{\beta}, \widehat{\theta}, \widehat{\phi}$, and $\widehat{\gamma}$ is obtained, we apply the grouping algorithm

\footnotetext{
${ }^{34}$ Andrews, Schank, and Upward (2004) suggest to use a two-step estimation which estimates the the firm effects in a first step and the full equation in a second step. Simulations show that the two-step method works pretty well for all but the person effects. The reason might be, that the two-step method does not estimate the person and the firm effect simultaneously and thus ignores the iterativ mechanism which is used in this paper.
} 
discussed in Abowd et al. (2002a) in order to establish the number of identified effects. We normalize the person constant, the firm constant, and firm tenure parameter to be relative to the mean value of this parameter within each group. Table 9 gives a summary of the results of the grouping procedure.

Table 9: Groups and Identifiable Effects

\begin{tabular}{|c|c|c|c|c|c|}
\hline & $\begin{array}{r}\text { not } \\
\text { connected }\end{array}$ & $\begin{array}{r}\text { Largest } \\
\text { Group }\end{array}$ & $\begin{array}{r}2^{\text {nd }} \text { Largest } \\
\text { Group }\end{array}$ & $\begin{array}{l}\text { Average of all } \\
\text { other Groups }\end{array}$ & $\begin{array}{r}\text { Total of all } \\
\text { Groups }\end{array}$ \\
\hline $\begin{array}{l}\text { main sample } \\
\text { Observations } \\
\text { Persons } \\
\text { Firms } \\
\text { Groups } \\
\text { Identifiable Effects }\end{array}$ & $\begin{array}{l}89,002 \\
21,560 \\
21,560\end{array}$ & $\begin{array}{r}1,956,062 \\
352,716 \\
83,535 \\
1 \\
436,250\end{array}$ & $\begin{array}{r}191 \\
30 \\
4 \\
1 \\
33\end{array}$ & $\begin{array}{r}11.70 \\
2.22 \\
1.73 \\
11,475\end{array}$ & $\begin{array}{r}2,090,483 \\
378,244 \\
103,346 \\
11,477 \\
470,113\end{array}$ \\
\hline $\begin{array}{l}\text { JTJ sample } \\
\text { Observations } \\
\text { Persons } \\
\text { Firms } \\
\text { Groups } \\
\text { Identifiable Effects }\end{array}$ & $\begin{array}{r}283 \\
88 \\
88\end{array}$ & $\begin{array}{r}365,706 \\
56,251 \\
33,441 \\
1 \\
89,691\end{array}$ & $\begin{array}{r}248 \\
33 \\
7 \\
1 \\
39\end{array}$ & $\begin{array}{r}8.61 \\
1.40 \\
2.40 \\
8,822\end{array}$ & $\begin{array}{r}441,900 \\
68,678 \\
54,586 \\
8,824 \\
114,440\end{array}$ \\
\hline $\begin{array}{l}\text { JUJ sample } \\
\text { Observations } \\
\text { Persons } \\
\text { Firms } \\
\text { Groups } \\
\text { Identifiable Effects }\end{array}$ & $\begin{array}{l}62 \\
32 \\
32\end{array}$ & $\begin{array}{r}271,527 \\
49,538 \\
40,886 \\
1 \\
90,423\end{array}$ & $\begin{array}{r}66 \\
9 \\
2 \\
1 \\
10\end{array}$ & $\begin{array}{r}6.01 \\
1.18 \\
2.33 \\
4,613\end{array}$ & $\begin{array}{r}299,310 \\
54,991 \\
51,630 \\
4,615 \\
102,006\end{array}$ \\
\hline
\end{tabular}

Source: ASSD, own calculations.

Note: The number of observations differs from table 1 because for some firms, the tenure slope parameter was not identified even though they are connected to a group. Results in the main text focus on firms with estimates for both entry wage $\phi$ and slope parameter $\gamma$.

We apply this procedure separately, to the main dataset, to the JTJ dataset, and to the JUJ dataset. Thus, we end up with three sets of parameters which we index by the dataset in which they were obtained. 


\section{Coefficient Estimates for Results in Table 4}

Table 10: Coefficient Estimates for Results in Table 4

\begin{tabular}{lrr}
\hline \hline Variable & Coef. & (SE) \\
\hline Experience & & \\
1 Year & $0.014^{* *}$ & $(0.001)$ \\
2-3 Years & $0.062^{* *}$ & $(0.001)$ \\
4-5 Years & $0.109^{* *}$ & $(0.001)$ \\
6-8 Years & $0.154^{* *}$ & $(0.001)$ \\
9-12 Years & $0.201^{* *}$ & $(0.001)$ \\
13-17 Years & $0.203^{* *}$ & $(0.001)$ \\
18 and more Years & $0.215^{* *}$ & $(0.001)$ \\
1991 & $0.039^{* *}$ & $(0.000)$ \\
1992 & $0.056^{* *}$ & $(0.000)$ \\
1993 & $0.068^{* *}$ & $(0.000)$ \\
1994 & $0.075^{* *}$ & $(0.000)$ \\
1995 & $0.092^{* *}$ & $(0.000)$ \\
1996 & $0.092^{* *}$ & $(0.000)$ \\
1997 & $0.098^{* *}$ & $(0.000)$ \\
Blue Collar & $-0.115^{* *}$ & $(0.000)$ \\
Nobs & \multicolumn{2}{c}{$2,090,483$} \\
$\mathrm{R}^{2}$ & \multicolumn{2}{c}{0.937} \\
\hline \hline
\end{tabular}

Source: ASSD, main sample, own calculations.

Note:** Significant at $1 \%$ level, ${ }^{*}$ Significant on $5 \%$ level

\section{Correlations}

Table 11: Correlation between Components of the Log Real Wage

\begin{tabular}{lrrrrrrrr}
\hline \hline Variable & lnwage & $\left(x^{\prime} \beta\right)$ & $(\theta)$ & $(\alpha)$ & $\left(u^{\prime} \nu\right)$ & $(\psi)$ & $(\phi)$ & $\left(\gamma^{\prime} s\right)$ \\
\hline Log(wage) & 1.000 & & & & & & & \\
Indiv. char. $\left(x^{\prime} \beta\right)$ & 0.485 & 1.000 & & & & & & \\
Person effect $(\theta)$ & 0.751 & 0.331 & 1.000 & & & & & \\
Unobs. PE $(\alpha)$ & 0.716 & 0.288 & 0.978 & 1.000 & & & & \\
Obs. PE $\left(u^{\prime} \eta\right)$ & 0.247 & 0.239 & 0.212 & 0.003 & 1.000 & & & \\
Firm effect $(\psi)$ & 0.408 & 0.024 & -0.265 & -0.278 & 0.034 & 1.000 & & \\
Unobs.FE $(\phi)$ & 0.348 & -0.021 & -0.200 & -0.211 & 0.026 & 0.831 & 1.000 & \\
Tenure $\left(\gamma^{\prime} s\right)$ & 0.104 & 0.077 & -0.112 & -0.118 & 0.014 & 0.294 & -0.288 & 1.000 \\
\hline \hline
\end{tabular}

Source: ASSD, main sample, own calculations.

Note: For a description of the samples see note of table (1).

Table 11 shows the correlation matrix of the components of the log real wage. To compare our results with the literature, we decompose $\theta_{i}$ into an unobservable part $\left(\alpha_{i}\right)$ and an observable part $\left(u_{i t}^{\prime} \eta\right.$; where $u_{i t}$ is education and age in 1990). The correlation structure appears to be rather similar to findings in Abowd et al. (2002a). We compare to their results because, to our knowledge, this is the only paper that is based on the full least squares solution. The correlation between the log real wage and $x^{\prime} \beta(0.485)$ in the main sample is slightly higher than the corresponding correlation in the Washington State sample (0.304) and much higher than in France (0.141). The person effect is very strongly correlated with the log real wage (0.751). This 
finding is also present in France (0.704) but to a weaker degree for Washington State (0.511). We find a correlation between the firm effect and the log real wage (0.408) that lies between the results for France (0.201) and for Washington State (0.518). The correlation between the person effect and the firm effect in Austria (-0.265) is very similar to that in France (-0.283) but more negative than the corresponding correlation in Washington State (-0.025). Thus, results for the main sample appear to be in line with findings in the literature. With respect to the details of the wage policy of the firm, we note that the starting wage $(\phi)$ is negatively correlated $(-0.288)$ with the seniority component of the wage rate $\left(\gamma^{\prime} s\right)$. 